\title{
Elucidation of Glutathione-S-transferase Activity Induced by Pectin- Cisplatin Nano-conjugates for Optimization of New Therapeutic Strategies Verma $\mathrm{AK}^{*}$ and Leekha $\mathrm{A}$
}

Nanobiotech Lab, Department of Zoology, KiroriMal College, University of Delhi, Delhi-110007, India

\begin{abstract}
Despite tremendous efforts to search novel drugs and treatments, cancer continues to be a major health hazard. Modulation of cellular responses to platinating agents has important clinical implications as they are still heavily prescribed against various cancers. First line chemotherapeutic drug used for treating solid tumors, displays dose limiting nephrotoxicity. Natural products are being sought in order to improve the anticancer efficacy of cisplatin. Pectin, a plant polysaccharide have reported strong anti-oxidant and anti-cancer properties. In our study, PectinCisplatin nanoconjugates in size range of $(200 \pm 20 \mathrm{~nm})$ were synthesized and assessed for their anti-cancer and renoprotective role. The cytotoxicity of Pec-cis nanoconjugates and cis per se was assessed and co-related with the Glutathione-s-transferase level in both, in-vitro (B-16/F-10 mouse melanoma cell line) and in-vivo models (C57BL6 mice) in time (24 hours, 48 hours) and dose dependent $(30 \mu \mathrm{g} / \mathrm{ml}$ and $60 \mu \mathrm{g} / \mathrm{ml}$ ) manner. Our findings revealed that pectin-cisplatinnanoconjugates exhibited cytotoxicity similar to the cisplatin solution at $1 / 10$ th of the cisplatin content, which indicates a possible synergism between the activity of the cisplatin and pectin. MDA and histological findings were corraborated for altered renal function in tumor bearing mice. Enhanced GST level was reported post pectincisplatin nanoconjugates administration which confirmed that pectin-cisplatin treatment ameliorated both functional and histopathologic damage. This was further verified by lowered MDA levels when compared to cisplatinper se. Therefore, our results confirmed that Pectin-cisplatin nanoconjugates exhibited anti-tumor properties and rendered partial protection against cisplatin induced nephrotoxicity thereby proving the biocompatibility of pectin-cisplatin nanoconjugates for therapeutic purposes.
\end{abstract}

Keywords: Pectin-Cisplatin nanoconjugates; Cytotoxicity; Glutathione-S-transferase; Oxidative stress; Nephrotoxicity

\section{Introduction}

Cisplatin (Cis), is still one of the most heavily prescribed chemotherapeutic drug for the treatment of a variety of malignancies that include ovarian, testicular and lung cancer [1] but has extremely low patient compliance owing to the induced nephrotoxicity. Acute kidney injury occurs after high-dose Cis chemotherapy in approximately $20 \%$ of patients [2] and it remains a significant cause of increased morbidity and mortality among patients, particularly in critical care units. Several therapeutic strategies are being used to prevent this condition mainly by vigorous hydration with normal saline is prevalent [3]. Inflammation and oxidative stress play a key role in Cis induced renal dysfunction [4]. Cis has been reported to enhance tumor necrosis factor-alpha (TNF-R) levels [5] superoxideanions [6], peroxynitrite anions [7], hydrogen peroxide [8], and hydroxyl radicals via mobilization of iron fromrenal cortical mitochondria $[9,10]$.

Cell death by cis is primarily initiated through the formation of intrastrand crosslinks, the majority of which involve neighbouring purine bases [11]. Accumulation of these adducts can inhibit DNA replication and transcription, triggering cell cycle arrest and apoptosis [12-14]. The severity of toxicity associated with this drug potentiates the development of newer approaches to combat cancer. Various studies demonstrated the protective effect of anti-inflammatory agents and antioxidants against Cis-induced inflammation and oxidative stress in experimental nephrotoxicity $[15,16]$. Cis-induced nephrotoxicity is closely associated with an increase of lipid peroxidation in the kidney tissues [17-19]. Furthermore, Cis induced glutathione depletion is a determinant step in oxidative stress in kidney tissue that leads to nephrotoxicity [20]. Cis chemotherapy induces a fall in plasma antioxidant levels, which may reflect a failure of the antioxidant defense mechanism against oxidative damage induced by commonly used antitumor drugs [21]. Renewed interest has been observed in recent years on the multiple activities of natural molecules. A large number of natural products and dietary components have been evaluated as potential chemoprotective agents. Natural compounds represent an important source of new "leads" with potent chemotherapeutic or chemopreventive activity [22].

Pectins (Pec) are complex plant polysaccharides present primarily in cell walls as an intercellular cementing material. Polysaccharides are preferred due to their unique and multifunctional attributes such as non-toxic, bio-compatible, biodegradable with adherence properties [23]. Pectin has been extensively investigated as matrix tablets for oral delivery to target the colon [24] and as microspheres [25-27].

Pectin per se (pec) and $\mathrm{pH}$ or heat-modified pectin have demonstrated chemopreventive and antitumoral activities against some aggressive and recurrent cancers [22]. It has been reported that polysaccharides in general have strong antioxidant activities and can be explored as novel potential antioxidants [28]. Due to their antioxidant activity, polysaccharides extracted from fungal, bacterial and plant sources have been proposed as therapeutic agents [29]. It has been recently reported that pectins and pectic acids have antioxidant activity that may be related to free radical scavenging activity of these molecules [30,31]. We have earlier communicated in depth physical

*Corresponding author: Anita Kamra Verma, Nanobiotech Lab, Department of Zoology, KiroriMal College, University of Delhi, Delhi-110007, India, Tel: 9818921222; E-mail: akverma@kmc.du.ac.in

Received May 17, 2016; Accepted July 21, 2016; Published July 28, 2016

Citation: Verma AK, Leekha A (2016) Elucidation of Glutathione-S-transferase Activity Induced by Pectin-Cisplatin Nano-conjugates for Optimization of New Therapeutic Strategies. J Nanomed Nanotechnol 7: 391. doi:10.4172/21577439.1000391

Copyright: ( 2016 Verma AK, et al. This is an open-access article distributed under the terms of the Creative Commons Attribution License, which permits unrestricted use, distribution, and reproduction in any medium, provided the original author and source are credited. 
characterization of pec-cisplatin(pec-cis) nanoconjugates and their therapeutic efficacy in a tumor model [32].

Reduced glutathione-GSH and GSTs are two primary lines of defense against both acute and chronic toxicities of electrophiles and reactive oxygen/nitrogen species. GSH confers cellular protection either directly, or by enzymatic reduction of free radicals, generation of reactive oxygen species (ROS), and conjugating endogenous and exogenous electrophiles. GSTs (cytosolic, mitochondrial and microsomal GSTs) are a family of Phase II detoxification enzymes that detoxify both ROS and toxic xenobiotics, including alkylating and platinating agents, primarily by catalyzing GSH-dependent conjugation and redox reactions. Overexpression of GST leads to an accelerated detoxification of drug substrates. The GSTs play a central role in the cellular metabolism of cytotoxic and carcinogenic compounds [33-35]. Distribution of GST family of enzymes in hepatic and extrahepatic tissues and other major organs is similar in humans and rodents [36]. Therefore, these animals make a good model for the study of GSTcatalyzed metabolism of anticancer drugs and toxins.

Our findings on the altered biodistribution of cis by pectincisplatinnanoconjugates (pec-cis) [32] warranted further understanding of the molecular and biochemical mechanism that played a key role in the cellular metabolism of cytotoxic and carcinogenic compounds. In the present study, cisper se and pec-cisnanoconjugates were evaluated for their anticancer and renoprotective role in B-16/F-10 mouse melanoma cell lines and C57BL/6 mice.

\section{Materials and Methods}

\section{Materials}

Analytical grade chemicals were purchased and used without further purification. Cis-diamminedichloroplatinum (II), pure pectin from citrus fruit having $87.6 \%$ Galacturonic acid residues with 9\% methoxylation, MTT [3-(4,5-dimethylthiazol-2-yl)-2,5diphenyltetrazolium bromide] and Sephadex G-25, were obtained from Sigma Chemicals St. Louis, U.S.A. The dialysis membrane Spectra/ Por-7; MWCO, $(10 \mathrm{kD})$ was procured from Spectrum Laboratories Inc, USA. (DMEM) (Gibco), Foetal Calf Serum (FCS) (Hi-media), HEPES (4-(2-hydroxyethyl)-1-piperazineethanesulfonic acid), $\mathrm{Na}_{2} \mathrm{HPO}_{4}$ $\mathrm{NaH}_{2} \mathrm{PO}_{4}$ and $\mathrm{NaCl}$ were procured from SRL Laboratories (India). Inbred male C57BL/6 mice (6 weeks old) weighing 18-20 g each, were obtained from the Institutional Small Animal Holding Facility. All the experiments were carried out in accordance with the protocols approved by IAEC under CPCSEA registration no.1666/PO/ac/12/CPCSEA.

\section{Preparation and characterization of nanoconjugates}

Pec-cisnanoconjugates were prepared as per our previously published protocol [11]. Briefly, cis $(1 \mathrm{mg} / \mathrm{ml})$ was added dropwise in a solution of temperature degraded pectin $(5 \mathrm{mg} / \mathrm{ml})$ with vigorous stirring for 48 hours. The particle size measurements (hydrodynamic radius, Rh) was estimated by dynamic Laser light scattering (DLS) having excitation source of He-Ne Gas laser with a wavelength of 633 $\mathrm{nm}$ and a power of $4 \mathrm{~mW}$ in a linearly polarized single frequency mode at $173^{\circ}$ scattering angle, using Zeta nano-ZS, backscattered (Malvern Instruments, USA). The electrophoretic mobility and surface charge of nanoparticles was further measured by the frequency shift of the scattered light at a $12^{\circ}$ scattering angle using Zeta Nano-ZS, (Malvern Instruments, UK) where a charged particle moves under the influence of an electric field in between the electrodes.

The size was further visualized and analyzed by the Nanosight
Tracking Analysis (NTA) Model NS 300, Malvern UK equipped with a sample chamber with a 640-nm laser and a Viton fluoro-elastomer O-ring. Using sterile syringes, requisite amount of samples were injected in the sample chamber till the liquid reached the tip of the nozzle. All measurements were performed at room temperature. The software used for capturing and analyzing the data was the NTA 2.0 Build 127. The samples were measured for $40 \mathrm{~s}$ with manual shutter and gain adjustments. The "single shutter and gain mode" was used to capture the Pec-Cis nanoconjugates. Measurements of the same sample were performed in triplicates. The error bars displayed on the NTA graphs were obtained by the standard deviation of the different measurements of each sample. The mean size and SD values obtained by the NTA software correspond to the arithmetic values calculated with the sizes of all the particles analyzed by the software.

\section{In-vitro cytotoxicity assays}

The B16-F10 mouse melanoma cell line was maintained in RPMI supplemented with $10 \%$ FCS in a $\mathrm{CO}_{2}$ incubator (Thermo Electron Corporation, Model BB-15) having 5\% $\mathrm{CO}_{2}$ and $95 \%$ humidity. A standard MTT assay [37] for 24 and 48 hours was performed in vitro. Briefly, B16-F10 cells were plated at a density of 5,000 cells/well in DMEM supplemented with 10\% FCS, 20 mM HEPES, penicillin (100 $\mathrm{U} / \mathrm{ml})$ and streptomycin $(100 \mu \mathrm{g} / \mathrm{ml})$ in a 96 well plate. MTT assay is based on the reduction of the tetrazolium salt into a blue purple formazon crystal, mainly by mitochondrial enzymes of living cells. After the requisite time period, $20 \mu \mathrm{l}$ of MTT solution $(5 \mathrm{mg} / \mathrm{ml})$ was added to each well. Formazan crystals were clearly visible post 4 hours of incubation. The formazan crystals formed by the cellular reduction of MTT were further dissolved in $100 \mu \mathrm{l}$ of DMSO. After mixing with a mechanical plate mixer and the plates were read on an ELISA-reader (SynergyHT, Biotek, USA) using a $570 \mathrm{~nm}$ filter. All measurements were done in triplicates. The relative cell viability (\%) related to control wells without nanoconjugates was calculated by:

Percent cytotoxicity $=\left\{[\mathrm{A}]_{\text {control }}-[\mathrm{A}]_{\text {test }} /[\mathrm{A}]_{\text {control }}\right\} \times 100$

where, $[\mathrm{A}]_{\text {test }}$ is absorbance of the test sample and

$[\mathrm{A}]_{\text {control }}$ is the absorbance of the control sample.

The color developed due to formation of formazan crystals was directly proportional to the viable population.

\section{Glutathione-S-transferase (GST) assay}

For GST activity, the cells were harvested 24 hrs post treatment of cisper se, pectin and Pec-cisnanoconjugates. The GST activity of the cell line and tissue homogenate was done by using 1-chloro-2,4dinitrobenzene (CDNB) and GSH according to the modified protocol of Habig et al, 1974 [38]. The rate of GST formation was monitored by measuring absorbance at $340 \mathrm{~nm}$ using UV/visible spectrophotometer (SynergyHT, Biotek, USA). Enzyme activity was calculated after normalizing for the non-enzymatic function.

\section{Lipid peroxidation measurement (Malionaldehyde)}

The free-radical modulation activity of Pec-Cis was determined using a lipid peroxidation assay. Kidneys were isolated post $7^{\text {th }}$ day and $14^{\text {th }}$ day treatment with PBS, Pec-Cis, Cis, Pec and $10 \%$ tissue homogenate was prepared. The samples were incubated at $37^{\circ} \mathrm{C}$ for 1 hour in a dark incubator. The reaction was inhibited by adding an equal volume of stop solution $[0.25 \mathrm{M} \mathrm{HCl}, 1.5 \%$ (wt/vol) trichloroacetic acid, and $0.375 \%$ (wt/vol) thiobarbituric acid]. These reaction mixtures were boiled for 15 minutes, cooled, and then centrifuged at 12,000 rpm 
Citation: Verma AK, Leekha A (2016) Elucidation of Glutathione-S-transferase Activity Induced by Pectin-Cisplatin Nano-conjugates for Optimization of New Therapeutic Strategies. J Nanomed Nanotechnol 7: 391. doi:10.4172/2157-7439.1000391

for 15 minutes. The absorbance of the resulting solution was measured at $532 \mathrm{~nm} \mathrm{[39].}$

\section{Histopathology}

The mice were sacrificed post 14 days of daily injections and the kidneys were aseptically removed and tissues were washed with PBS. The kidney slices were fixed in neutral buffered formalin for 3 hours and gradient dehydration was done by $50 \%, 70 \%, 80 \%, 90 \%$ and absolute ethanol. The tissue was further embedded in paraffin wax and sections of 3-5 $\mu \mathrm{m}$ thickness were taken and stained with Haemotoxylin and Eosin using the standard protocol [40].

\section{Statistical analysis}

The results were expressed as mean \pm SD. Comparison among groups were analyzed by One-way Anova and means were separated by Tukey's test using Prism (5.0) software (Prism Software Inc. CA). Levels of significance were accepted at $\leq 0.05$.

\section{Results}

The nanoconjugates were formed by the spontaneous folding caused by the coordination bond between the platinum atom and the carboxylic group in galacturonate of pectin [37]. In our earlier communication, we have verified the complex and reported a detailed physical characterization and release profile in plasma [41].

The NanoSight NS300 nanoparticle tracking analysis system (NTA) enables sample visualization and provides approximate particle concentrations in suspension, without affecting quality or functionality, all of which are very extremely useful features for particle characterizations. The size of pec-cisnanoconjugates was measured by DLS, and was in the range of $200 \pm 20 \mathrm{~nm}$ with a PDI of 0.35 . Zeta potential, being a useful indicator of surface charge property that confers stability to the nanoconjugate was observed to be $-25.7 \mathrm{mV}$ (Figure 1).
In our previous study it was observed that pec-cisnanoconjugates were stable and exhibited slow and a sustained release system with no burst effect. The measurement of the pectin-cisplatin conjugate depicts that the highly polyanionic pectin chains get shielded, $\sim 7$ times, on addition of cisplatin that may help in enhancing its interaction with cell membranes and prevents intra-molecular aggregation of the nanoconjugates [32].

The cytotoxicity was evaluated in a dose and time dependent manner at two time points i.e. 24,48 hours and with two doses i.e. $200 \mu \mathrm{M}(60 \mu \mathrm{g} / \mathrm{ml})$ and $100 \mu \mathrm{M}(30 \mu \mathrm{g} / \mathrm{ml})$. The percent cytotoxicity of cisper se, pec-cis and pec at concentration of $60 \mu \mathrm{g} / \mathrm{ml}$ was reported to be $68.6 \pm 3.8 \%, 57.6 \pm 2.7^{* *} \%, 3.3 \pm 0.7$ whereas at a concentration of $30 \mu \mathrm{g} / \mathrm{ml}, 75.7 \pm 2.1 \%, 65.4 \pm 3.5 \%, 3.3 \pm 0.7 \%$ cytotoxicty was observed post 24 hours of treatment. Post 48 hours of treatment, cis per se, pec-cis and pec at concentration of $60 \mu \mathrm{g} / \mathrm{ml}$ exhibited $74.1 \pm$ $4.0 \%, 68.1 \pm 3.3 \%, 3.2 \pm 1.7 \%$ cytotoxicity whereas at concentration of $30 \mu \mathrm{g} / \mathrm{ml}, 80.8 \pm 2.1 \%, 70.6 \pm 2.8 \%, 4 \pm 0.9 \%$ cytotoxicity was reported. In our study, we evaluated the correlation of cytotoxicity with the glutathione-S-transferase activity. The GST levels were evaluated at two time points i.e. in dose $(60 \mu \mathrm{g} / \mathrm{ml}$ and $30 \mu \mathrm{g} / \mathrm{ml})$ and time $(24$ hours and 48 hours) dependent manner. At a concentration of $60 \mu \mathrm{g} /$ $\mathrm{ml}$, GST level post cis per se, pec-cis and pec treatment was reported to be $3 \pm 1.1 \mathrm{~nm} / \mathrm{mg}, 18.6 \pm 2.1^{+++} \mathrm{nM} / \mathrm{mg}, 19.1 \pm 0.5 \mathrm{nM} / \mathrm{mg}$ whereas at a concentration of $30 \mu \mathrm{g} / \mathrm{ml}, 5.2 \pm 1.1 \mathrm{nM} / \mathrm{mg}, 10.7 \pm 1.6^{+} \mathrm{nM} / \mathrm{mg}$, $11.2 \pm 0.5 \mathrm{nM} / \mathrm{mg}$ GST levels were reported post 24 hours of treatment. Post 48 hours of treatment, cisper se, pec-cis and pec at concentration of $60 \mu \mathrm{g} / \mathrm{ml}$ exhibited $2.1 \pm 0.6 \mathrm{nM} / \mathrm{mg}, 23.2 \pm 1.6^{+++} \mathrm{nM} / \mathrm{mg}, 25 \pm 1.2$ $\mathrm{nM} / \mathrm{mg}$ GST levels whereas at concentration of $30 \mu \mathrm{g} / \mathrm{ml}$, The reported GST levels were $5.1 \pm 0.8 \mathrm{nM} / \mathrm{mg}, 14.8 \pm 2.8^{++} \mathrm{nM} / \mathrm{mg}, 15.7 \pm 1.0 \mathrm{nM} /$ mg respectively. From our results, it was found that in B16-F10 mouse melanoma cell line, cytotoxicity was inversely proportional to the GST levels (Figure 2 and Table 1).
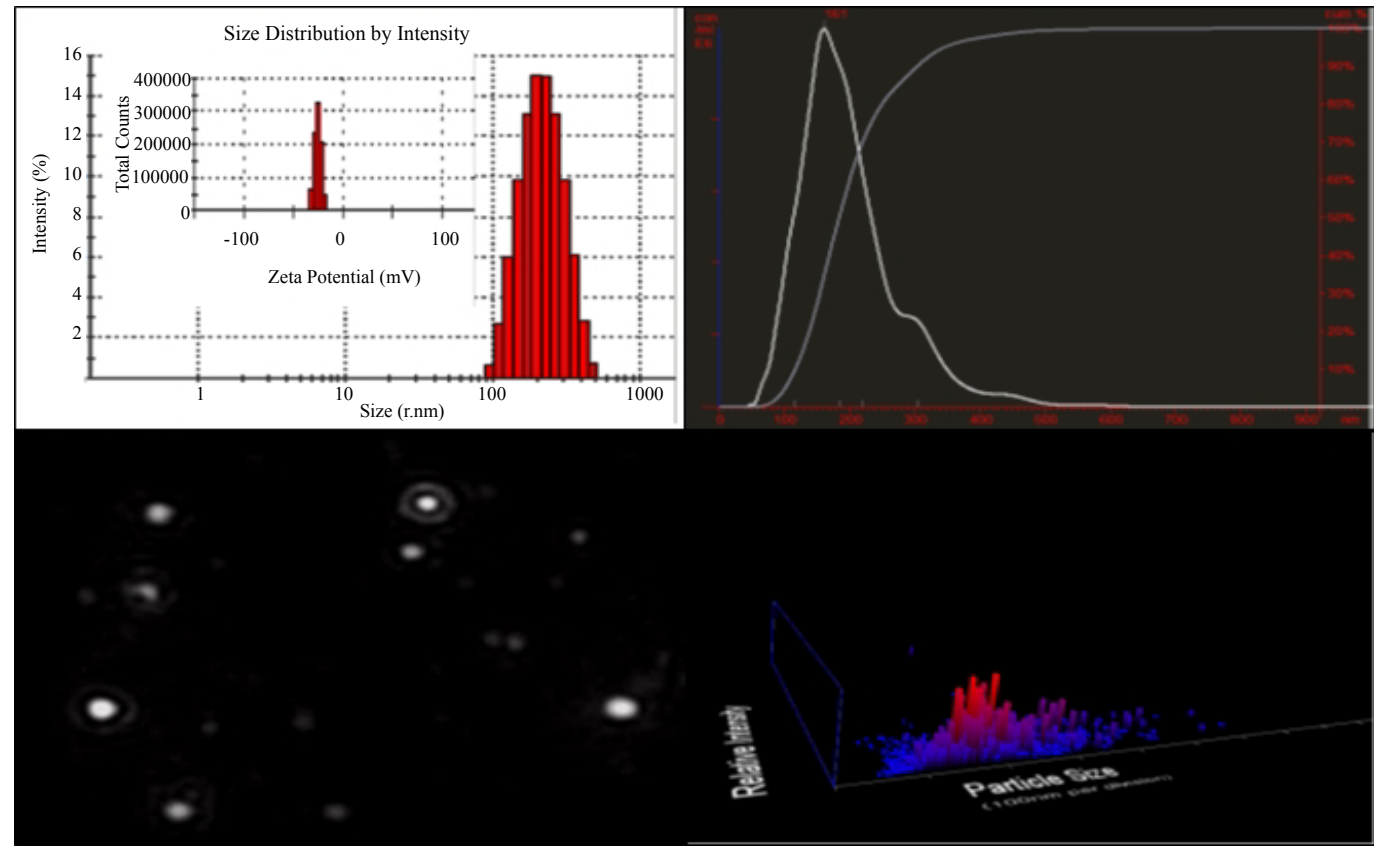

Figure 1: Dynamic Light Scattering measurement of pec-cisnanoconjugate at room temperature. The Z-Average diameter of the nanoconjugate is $214.14 \mathrm{~nm}$ \pm 18.68 with a 0.351 polydispersity index. The overall charge was $-25.7 \mathrm{mV} \pm 3.78$. The electrophoretic mobility of the particle was $-2.016 \mu \mathrm{mcm} / \mathrm{Vs}$. Pec-Cis nanoconjugate measured with Nanosight Tracking Analysis [NTA]. The size distribution (middle panels) with the corresponding NTA video frame (left panels) and 3D graph (size vs. intensity vs. concentration; right panels) are shown. 
Citation: Verma AK, Leekha A (2016) Elucidation of Glutathione-S-transferase Activity Induced by Pectin-Cisplatin Nano-conjugates for Optimization of New Therapeutic Strategies. J Nanomed Nanotechnol 7: 391. doi:10.4172/2157-7439.1000391

The pec-cis nanoconjugate have a drug loading of $49 \%$. Therefore, at a concentration of $60 \mu \mathrm{g} / \mathrm{ml}$ and $30 \mu \mathrm{g} / \mathrm{ml}$, the pec-cisnanoconjugate are capable of producing a maximal cis per se concentration of $5.88 \mu \mathrm{g} /$ $\mathrm{ml}$ and $2.94 \mu \mathrm{g} / \mathrm{ml}$ respectively. Comparing these concentrations with that of the cis per se solution tested $60 \mu \mathrm{g} / \mathrm{ml}$ and $30 \mu \mathrm{g} / \mathrm{ml}$, we observed that the pec-cis nanoconjugates are capable of bringing about the same effect as that of the free cis at very low pec-cis dosage (Table 2). This confirms the synergistic effect of pec-cis conjugation. Results from the MTT cytotoxicity assay, high $\mathrm{IC}_{50}$ value (Table 2) of pec validate the excellent biocompatibility of the pec-cis nanoconjugates.

GSTs catalyze the nucleophilic attack of the sulfur atom of GSH on the electrophilic group of numerous types of xenobiotics and could also detoxify anticancer drugs not only by acting directly on the molecules but rather on a metabolite [42]. This drastically reduces the reactivity of these compounds and makes them more water soluble, so as to enable their elimination. As a result, the GST catalytic activity may play a key role in the detoxification of a variety of anticancer drugs such as, Cis, melphalan, chlorambucil, cyclophosphamide, bis-

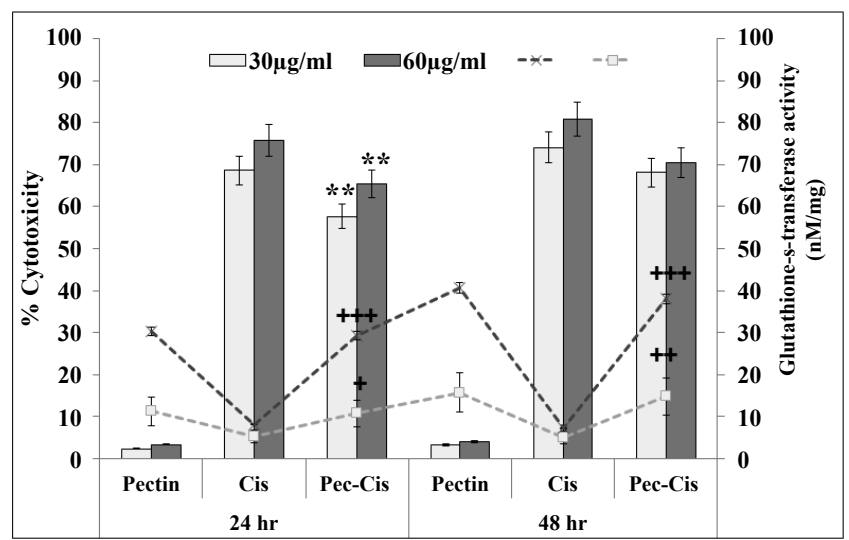

Figure 2: The comparative graph of GST activity vs. cytotoxicity at $30 \mu \mathrm{g} / \mathrm{m}$ and $60 \mu \mathrm{g} / \mathrm{ml}$ of cis in B16-F10 mouse melanoma cell line. *indicates significan difference between $\mathrm{Cis}$. And pec-cis (\% cell cytotoxicity). + indicates significan difference between Cis. And pec-cis (GST level). ${ }^{\star \star *} \mathrm{P}<0.005$, ${ }^{\star *} \mathrm{P}<0.05$, ${ }^{*} \mathrm{P}<0.5$. chloroethylnitrosourea (BCNU), mitoxantrone and thiotepa [43]. Microsomal GST is a membrane protein that has been extensively expressed in most tissues. Experimentally, the highest expression was observed in the liver i.e $285.49 \pm 4.64 \mathrm{nM} / \mathrm{mg}$ protein. Results presented in this study are in support with studies demonstrating that highest levels of Glutathione family enzymes in mice are in the liver [44]. This confirmed that the liver is the major organ responsible for the detoxification of various exogenous and endogenous toxicants. Likewise, kidneys, lungs and brain that are also exposed to toxicants also possess their own GSH, GST activity [45]. The proof of concept studies clearly indicated the upregulation of GST in all tissues that are primarily responsible for detoxifying the cells. Hence, it was only natural that the study progressed from in-vitro to in-vivo. The tumor bearing mice were treated with Pectin, Pec-cis nanoconjugate and cisper se, and the levels of GST evaluated. Kidney exhibited a maximum increase $\left(99.74 \pm 2.35 \mathrm{~nm}^{* * *}\right)(\mathrm{p} \leq 0.005)$ of GST activity while in liver, spleen and tumor, the GST levels were also significantly enhanced ( $p$ $\leq 0.005)$ i.e. $134.59 \pm 2.89^{* * *}, 74.98 \pm 2.96^{* * *}, 70.49 \pm 2.23^{* * *}$ respectively post 7 days of treatment (Figure 3). However, 14 days post treatment, the GST activity in spleen and kidney was relatively reduced when compared to liver. But, in all the organs, pec-cis enhanced the GST level which shows its protective effect.

indicates significant difference between cis. Andpec-cis, ${ }^{* * *} \mathrm{P}<$ $0.005,{ }^{* *} \mathrm{P}<0.05,{ }^{*} \mathrm{P}<0.5$

Decrease in the activities of renal Glutathione enzymes are proof of the oxidative stress caused by Cis treatment and have been previously reported in a number of previous studies [46-48]. These observations support the mechanism that nephrotoxicity induced by Cis in mice was partially related to the depletion of renal antioxidant system. As GST [49] is one of the components of the antioxidant defense system of the cells, the increase caused by Pectin conjugation could be one of the mechanisms by which Pectin acts as a protective agent in the kidneys of mice.

To highlight ROS production, we performed lipid peroxidation experiments. The oxidation of fatty acids leads to the generation of lipid peroxides, thereby initiating a chain reaction that results in the

\begin{tabular}{|c|c|c|c|c|c|}
\hline \multirow{2}{*}{ Samples } & \multirow{2}{*}{ Concentration } & \multicolumn{2}{|c|}{$\%$ Cytotoxicity } & \multicolumn{2}{|c|}{ GST (nM/mg protein) } \\
\hline & & 24 Hours & 48 Hours & 24 Hours & 48 Hours \\
\hline Pectin & \multirow{2}{*}{$30 \mu \mathrm{g} / \mathrm{ml}$} & $2.3 \pm 0.6$ & $3.2 \pm 1.7$ & $11.2 \pm 0.5$ & $15.7 \pm 1.0$ \\
\hline Cis & & $68.6 \pm 3.8$ & $74.1 \pm 4.0$ & $5.2 \pm 1.1$ & $5.1 \pm 0.8$ \\
\hline Pec-cis & $30 \mu \mathrm{g} / \mathrm{ml}(2.94 \mu \mathrm{g} / \mathrm{mlcis})$ & $57.6 \pm 2.7^{* *}$ & $68.1 \pm 3.3$ & $10.7 \pm 1.6^{+}$ & $14.8 \pm 2.8^{++}$ \\
\hline Pectin & \multirow{2}{*}{$60 \mu \mathrm{g} / \mathrm{ml}$} & $3.3 \pm 0.7$ & $4 \pm 0.9$ & $19.1 \pm 0.5$ & $25 \pm 1.2$ \\
\hline Cis & & $75.7 \pm 2.1$ & $80.8 \pm 2.1$ & $3 \pm 1.1$ & $2.1 \pm 0.6$ \\
\hline Pec-cis & $60 \mu \mathrm{g} / \mathrm{ml}(5.88 \mu \mathrm{g} / \mathrm{mlcis})$ & $65.4 \pm 3.5^{* *}$ & $70.6 \pm 2.8$ & $18.6 \pm 2.1^{+++}$ & $23.2 \pm 1.6^{+++}$ \\
\hline \multicolumn{6}{|c|}{$\begin{array}{l}\text { "Significant difference between cis. andpec-cis (\% cell cytotoxicity). } \\
+ \text { Significant difference between cis. andpec-cis (GST level). } \\
{ }^{* *} \mathrm{P}<0.005,{ }^{* *} \mathrm{P}<0.05,{ }^{*} \mathrm{P}<0.5 \text {. }\end{array}$} \\
\hline
\end{tabular}

Table 1: Comparative analysis of \% Cytotoxicity and GST level on B-16/F-10 mouse melanoma cells.

\begin{tabular}{|c|c|c|c|}
\hline \multirow{2}{*}{ Samples } & \multirow{2}{*}{ Concentration } & \multicolumn{2}{|c|}{$\mathrm{IC}_{50}$ values $(\mu \mathrm{g} / \mathrm{ml})$} \\
\hline & & 24 Hours & 48 Hours \\
\hline Pectin & \multirow{2}{*}{$30 \mu \mathrm{g} / \mathrm{ml}$} & 652 & 468.75 \\
\hline Cis & & 21.86 & 20.24 \\
\hline Pec-cis & $30 \mu \mathrm{g} / \mathrm{ml}(2.94 \mu \mathrm{g} / \mathrm{mlcis})$ & 2.55 & 2.14 \\
\hline Pectin & \multirow{2}{*}{$60 \mu \mathrm{g} / \mathrm{ml}$} & 909.09 & 750 \\
\hline Cis & & 39.63 & 37.12 \\
\hline Pec-cis & $60 \mu \mathrm{g} / \mathrm{ml}(5.88 \mu \mathrm{g} / \mathrm{mlcis})$ & 4.49 & 4.164 \\
\hline
\end{tabular}

Table 2: Assessment of $\mathrm{IC}_{50}$ values $(\mu \mathrm{g} / \mathrm{ml})$ post cis per se, pec-cis, pec treatment (24 hours and 48 hours). 


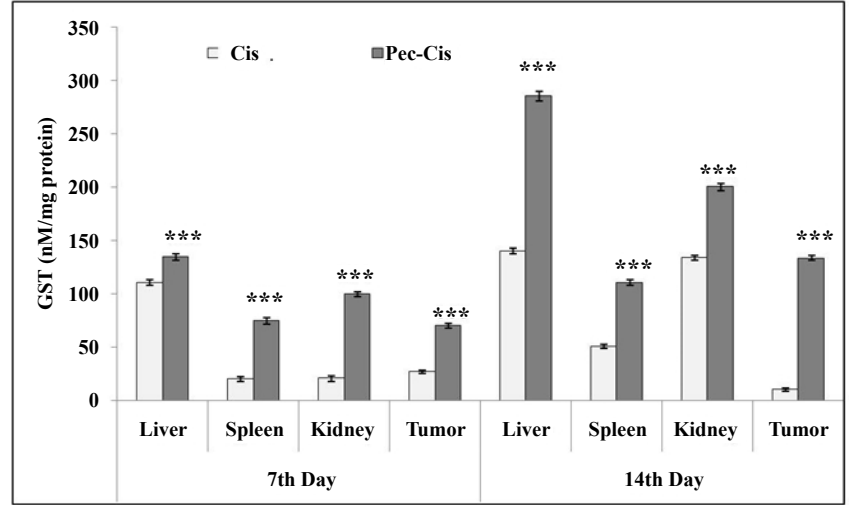

Figure 3: The GST activity 7 and 14 days post treatment. * indicates significan difference between cis. and pec-cis, ${ }^{* * *} \mathrm{P}<0.005,{ }^{* *} \mathrm{P}<0.05$, ${ }^{*} \mathrm{P}<0.5$.

disruption of the plasma and organelle membranes and subsequent cell death [50]. Malondialdehyde (MDA), a degradation product from lipid hydroperoxide, provides an index of the peroxidation of lipids in biological tissue. It is well documented that cis causes lipid peroxidation in the kidneys via ROS generation [51]. In this study, Pec-cis significantly attenuated lipid peroxidation in C57/BL6 mice, providing convincing evidence for the involvement of ROS in cis-induced lipid peroxidation.

Lipid peroxidation was enhanced post treatment with Cisper se i.e $11.48 \pm 1.443 \mathrm{nM} / \mathrm{mg}$ protein when compared to PBS but when pec-cis was administered a downregulation in the level of MDA was observed i.e $7.528 \pm 0.087 \mathrm{nM} / \mathrm{mg}$ when compared to cis per se post $7^{\text {th }}$ day treatment. Parallel results were obtained post 14 days of treatment indicating the potential of pectin in ameliorating the excess production of free radicals leading to reduced nephrotoxicity post pec-cis treatment as compared to cis treatment.

Although, it has now been postulated that severe nephrotoxicity can be prevented by employing aggressive hydration [52], renal function impairment after treatment of cis is being regularly encountered among patients. Furthermore, the exact mechanism how nephrotoxicity is produced has not been established. The renal toxicity induced by cis is primarily tubular dysfunction, hence it was necessary to study the histopathology of kidney to assess the damage caused by daily injections of cis and pec-cisnanoconjugates post 7 days and 14 days (dose: $1 \mathrm{mg} /$ $\mathrm{ml}$ ) of treatment.

Kidney slices from cis $(30 \mu \mathrm{g} / \mathrm{ml})$ pre-treated C56BL/6 mice exhibited morphological changes consistent with acute nephrosis in the convoluted tubules within the cortex and at the junction between the cortex and the outer margin of the medulla. The nephrosis was reduced in the pec-cis treated mice as evident by swelling and vacuolation, loss of normal histologic architecture, and multifocal areas of tubular epithelial cell degeneration and necrosis. The severity of the nephrosis was time dependent with the earliest lesions observed within 7 days (Figure 4). It was observed that the extent of swelling and necrosis progressed and involved all parts of the convoluted tubules in the tissues of mice post 14 days of cisper se and pec-cis administration.

The high doses ofcisis known to cause hepatocellular injury, therefore, it was imperative to assess the liver glutathione levels. Kidney being the filtering unit, was unable to retain the nanoconjugates and there was negligible damage to the kidney glomeruli, but there was significant damage by cis per se (Figure 5).

Cisis the preferredchemotherapeutic agentowing to its efficacyand the small size that enables it toaccumulate within cells by passive diffusion [53]. Accumulation of Cis in kidney could be explained as free $\mathrm{Cl}^{-}$of cis moleculesinteract with kidney cells while performing electrolyte homeostasis. But as pec-cisnanoconjugates, the $\mathrm{Cl}^{-}$atom was conjugated with carboxylic group (-COOH) of pectin chain, and hence it was cleared from kidney leading to reduced nephrotoxicity [32].

We have earlier reported an altered bio-distribution of cis with pec-cis nanoconjugates [41]. Our earlier reports have clearly indicated a three-fold tumor regression with the pec-cis conjugates when compared to cis per se [32]. The key factor that severely limits the cis cytotoxic efficacy in several human tumors may be the activity of cellular glutathione (GSH)-related detoxification system.

To further understand the mechanism of cellular detoxification, the role of glutathione-S-transferase was assessed. Formation of GSH-Cis metabolite is a major route for cellular elimination of Cis [45]. Literature suggest a strong link between overexpression of GST and development of nephrotoxicity from both in vivo studies and cell culture Cis metabolites are toxic through a GSH-conjugate intermediate mimicking the halogenated alkenes. Platinum-GSH conjugates may be formed in either the liver or the kidney. Studies with $195 \mathrm{mPt}$-labeled Cis showed that following injection, the highest levels of platinum are found in the liver and kidney [54,55]. In mice, systemic inhibition of GSTs with ketoprofen reduced Cis nephrotoxicity [56]. Above data clearly demonstrates the enzymatic activation of to a metabolite (diglutathionyl platinum) that is more toxic than the parent compound.

But for the first time, we have verified the involvement of GST and MDA levels in the protective activity of pectin in renal injury. Although, many studies have reported the elevated level of GST with enhanced toxicity, few have been reported to enhance GST levels coupled with amelioration of cytotoxicity by lowered MDA with Peccis administration culminating into reduced oxidative stress. This data may appear to contradict the above hypothesis but there have been reports in the literature that suggest the role of oxidative stresses in Cisinduced nephrotoxicity [8]. Evidences suggest that cisadministration caused remarkable deterioration in antioxidant defense as evidenced by decreased antioxidant enzymes and increased thiobarbituric acid reactive substances (TBARS) in renal tissues. The oxidative stress mainly results from formation of Cis-GSH conjugation [57]. The conjugation contributes to GSH depletion and alteration of redox state in kidney and consequently leads to an increase in generation of superoxide and other free radicals [58]. It is obvious that the nephrotoxicity of Cis involves

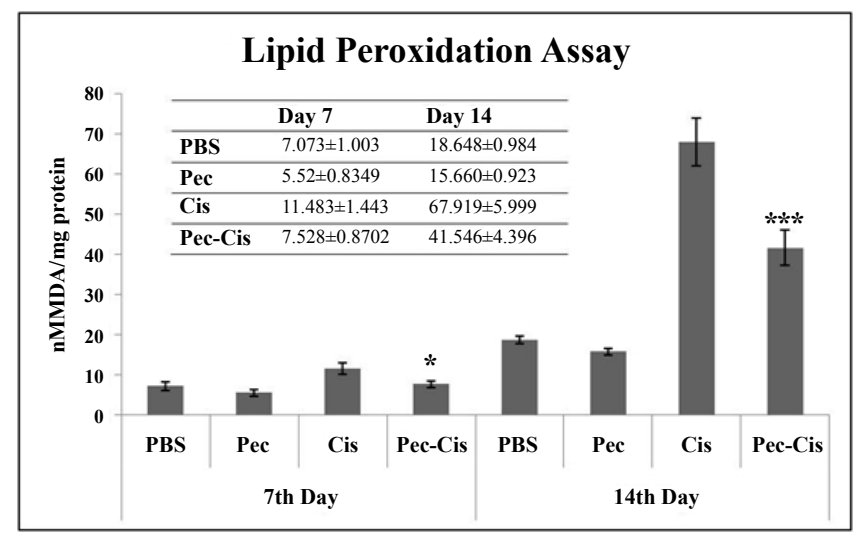

Figure 4: Graph depicting lipid peroxidation in Liver and Kidney $(n=5)$ [Bars represent mean of 5 values]. * indicates significant difference between cis. and pec-cis. ${ }^{* *} \mathrm{P}<0.005,{ }^{* \star} \mathrm{P}<0.05,{ }^{*} \mathrm{P}<0.5$. 
Citation: Verma AK, Leekha A (2016) Elucidation of Glutathione-S-transferase Activity Induced by Pectin-Cisplatin Nano-conjugates for Optimization of New Therapeutic Strategies. J Nanomed Nanotechnol 7: 391. doi:10.4172/2157-7439.1000391

Page 6 of 9

reactive radicals. Thus the reasonable cellular protective agents against Cis toxicity involve antioxidant mechanisms to prevent GSH depletion and/or scavenge the intracellular reactive oxygen species.

Free Radical Scavenging activity and enhanced antioxidant potential of pectin has already been reported [30,31]. On conjugation of pec with cis, diglutathionylplatinum compound is not formed due to which GST activity is enhanced providing better antioxidant potential therefore imparting reduced nephrotoxicity. Therefore, we have tried to elucidate the possible mechanism involved in the cellular uptake of Pec-cis nanoconjugates. Cis being a low molecular weight, passively enters the tumor cells by crossing the plasma membrane, but the polymer-drug conjugates are internalized possibly by receptormediated endocytosis $[59,60]$ high concentration of pec per se, has the ability to induce apoptotis in tumor cells [61]. The plasma membrane copper transporter-1 (CTR-1), a member of SLC family helps in the transport of Cis and its analogues across the cell [62]. Cis is released from the conjugate by hydrolysis, that possibly undergoes a second hydrolysis inside the cells. Once internalized, cis undergoes aquation to become a potent electrophile that reacts with a number of targets including a variety of endogenous nucleophiles (glutathione, metallothionein), nucleic acids and sulfhydryl group of proteins [63]. But studies have reported, the major intracellular metabolite of cis is diglutathionyl platinum [45], we tried to examine the formation of this toxic compound by assessing the MDA levels in kidney of mice as This compounds leads to elevated lipid peroxidation. The cis binds to the antioxidant molecule GSH, a reaction catalyzed by GST leading to the formation of diglutathionyl platinum which are effluxed out from the tumor cell via the ATP-dependent copper transporters ATP-7A and ATP-7B and the glutathione-conjugated efflux pump (MRP).

The pec-cis nanoconjugates are internalized into the cell and enter the endosome where they undergo distortion in their self-folding ability. The action of pectinolytic enzymes on the pec-cis nanoconjugate may also lead to the leaching of pectin and formation of pores for drug release [64-67]. Reports suggest that only $1 \%$ of Cis reacts with genomic DNA, whereas most part of the drug interacts with proteins, RNA, and small thiol compounds $[68,69]$.
DNA is the primary target of the internalized cis as the platinum atom of cis binds to the N-7 position on the purine bases mainly forming 1,2-intrastand crosslinks [53,63]. Due to the formation of PtDNA adducts, conformational changes in the DNA occur impeding the separation of both strands of DNA leading to the inhibition of DNA replication. The DNA damage response is transduced mainly via p53, $\mathrm{c}$-abl and PKC. Intercalation of cis into DNA activates recognition proteins that send the DNA damage signals to downstream effectors. The outcome of the Cis exposure depends on the relative intensity of the signal generated and the crosstalk among these pathways (Figure 6) $[63,70]$.

Haemotoxylin and Eosin stained sections of the kidney were assessed for the evidence of renal damage. The proximal tubules in the control mice showed no damage in the cortico-medullary region post 7 and 14 days treatment. Cellular debris was observed in cis treated mice with distinct damage to the tubules and glomeruli. The renal damage caused by pectin nanoconjugates was negligible and the architecture was similar to the control mice. Histopathological studies also corroborated the effects of elevated levels of GST in pectin nanoconjugate treated mice as evidenced by the negligible damage to the renal architecture when compared to cis per se.

\section{Conclusion}

Cis toxicity is multi-factorial, with several different mechanisms occurring simultaneously. Cis-induced nephrotoxicity was confirmed by assessing the anti-oxidant mechanisms. We found that Pec-cis nanoconjugates are more effective for the treatment of solid tumors and in ameliorating cis induced nephrotoxicity as pectin that is a known free radical quencher. In addition, nano-conjugation resulted in improved bioavailability, enhanced efficacy and renoprotection. The microsomal concentration of GST was inversely proportional to cytotoxicity. We conclude that GST in pec-cis treated cell (in-vitro) was higher than the cis treated cells that indicated nanoconjugates were less toxic and a better delivery system that may augment the activity of cis. GST activity in tissues (in-vivo) had a similar pattern as in-vitro. Pec-cis nanoconjugates have therapeutic potential for effective anticancer molecule that will pave the way for reducing mortality caused

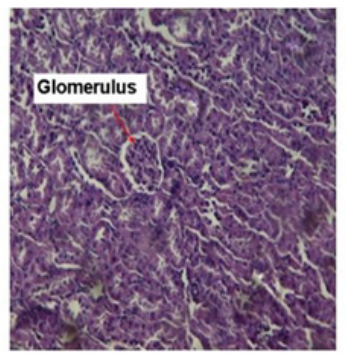

Control (7 Days)

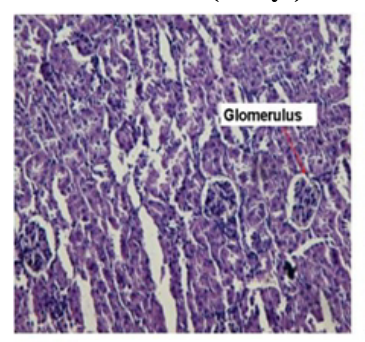

Control (14 Days)

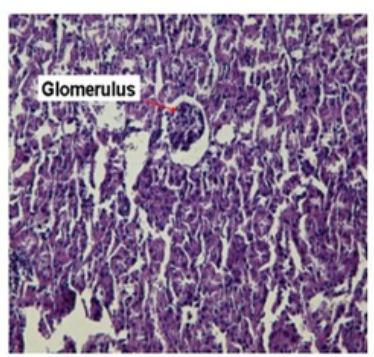

Cis (7 Days)

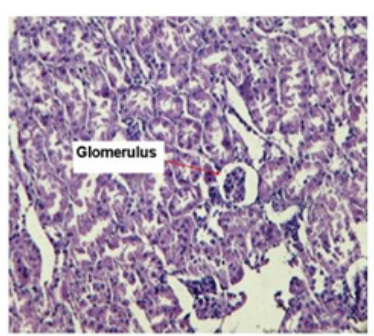

Cis (14 Days)

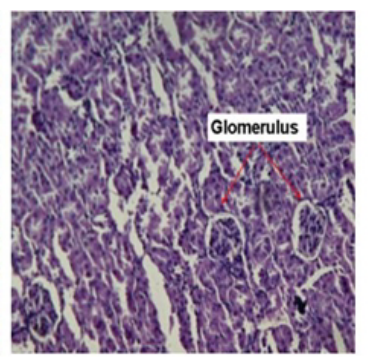

Pec-Cis (7 Days)

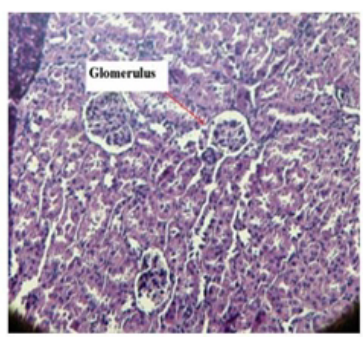

Pec-Cis (14 Days)

Figure 5: Morphology of mice kidney (Control 7 days and 14 days), Magnification is 40x. 
Citation: Verma AK, Leekha A (2016) Elucidation of Glutathione-S-transferase Activity Induced by Pectin-Cisplatin Nano-conjugates for Optimization of New Therapeutic Strategies. J Nanomed Nanotechnol 7: 391. doi:10.4172/2157-7439.1000391

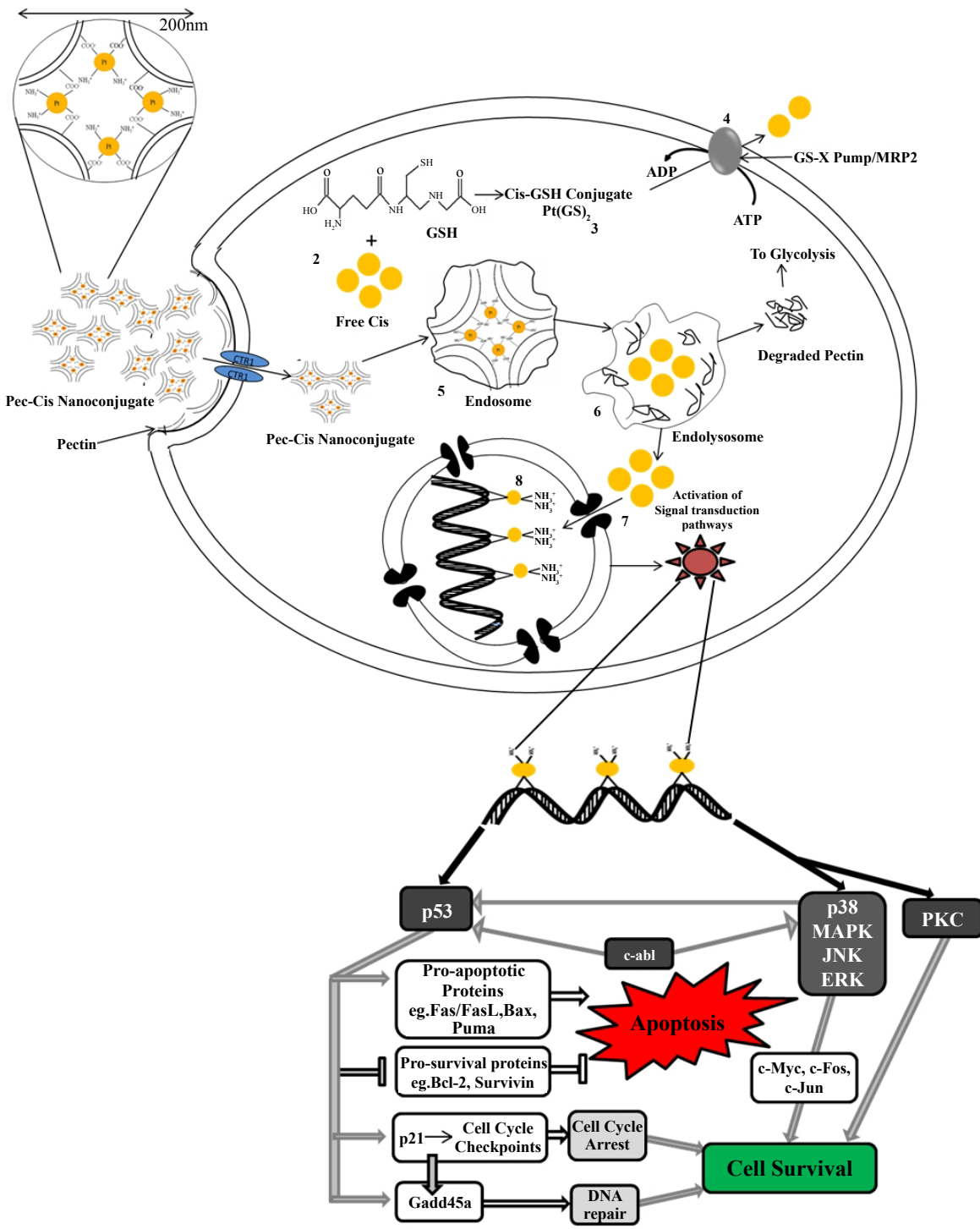

Figure 6: Proposed mechanism depicting the fate of Pec-cisplatin nanoconjugates.

by tumors. Although, detailed mechanism are quite essential to prove the results.

\section{Acknowledgements}

AL is thankful to JMI for her non-NET fellowship. A. Chanchal is duly acknowledged for initiating this work in 2007.

\section{Conflict of Interest}

None declared.

\section{References}

1. Kufe DW, Bast RC, Hait WN, Hong WK (2006) Cancer Medicine (7thedn) Hamilton, Ontario: BC Decker Inc 517-536.

2. Yao X, Panichpisal K, Kurtzman N, Nugent K (2007) Cisplatin nephrotoxicity: a review. Am J Med Sci 334: 115-124.

3. Launay-Vacher V, Rey JB, Isnard-Bagnis C, Deray G, Daouphars M (2008) Prevention of Cis nephrotoxicity: State of the art and recommendations from the European Society of Clinical Pharmacy Special Interest Group on Cancer Care. Cancer ChemotherPharmacol 61: 903-909.
4. Saad SY, Arafah MM, Najiar TA (2007) Effects of mycophenolate mofetil on cisplatin-induced renal dysfunction in rats. Cancer Chemother Pharmacol 59: 455-460.

5. Ramesh G, Reeves WB (2002) TNF-alpha mediates chemokine and cytokine expression and renal injury in cisplatin nephrotoxicity. J Clin Invest 110: 835842

6. Davis CA, Nick HS, Agarwal A (2001) Manganese superoxide dismutase attenuates Cisplatin-induced renal injury: importance of superoxide. J Am Soc Nephrol 12: 2683-2690.

7. Srivastava RC, Farookh A, Ahmad N, Misra M, Hasan SK, et al. (1996) Evidence for the involvement of nitric oxide in cisplatin-induced toxicity in rats. Biometals 9: 139-142.

8. Baek S, Kwon C, Kim J, Woo J, Jung J, et al. (2003) Differential roles of hydrogen peroxides and hydroxyl radical in $\mathrm{Cis}$ induced cell death in renal proximal tubular epithelial cells. J Lab Clin Med 142: 178-186.

9. Baliga R, Ueda N, Walker PD, Shah SV (1999) Oxidant mechanisms in toxic acute renal failure. Drug Metab Rev 31: 971-997.

10. Durak I, Ozbek H, Karaayvaz M, Oztürk HS (2002) Cisplatin induces acute renal failure by impairing antioxidant system in guinea pigs: effects of antioxidant supplementation on the cisplatin nephrotoxicity. Drug Chem Toxicol 25: 1-8. 
Citation: Verma AK, Leekha A (2016) Elucidation of Glutathione-S-transferase Activity Induced by Pectin-Cisplatin Nano-conjugates for Optimization of New Therapeutic Strategies. J Nanomed Nanotechnol 7: 391. doi:10.4172/2157-7439.1000391

11. Zlatanova J, Yaneva J, Leuba SH (1998) Proteins that specifically recognize cisplatin-damaged DNA: a clue to anticancer activity of cisplatin. FASEB $\mathrm{J} 12$ 791-799.

12. Ciccarelli RB, Solomon MJ, Varshavsky A, Lippard SJ (1985) In vivo effects of cis- and trans-diamminedichloroplatinum(II) on SV40 chromosomes: differential repair, DNA-protein cross-linking, and inhibition of replication. Biochemistry 24 7533-7540.

13. Demarcq C, Bunch RT, Creswell D, Eastman A (1994) The role of cell cycle progression in cisplatin-induced apoptosis in Chinese hamster ovary cells. Cell Growth Differ 5: 983-993.

14. Mello JA, Lippard SJ, Essigmann JM (1995) DNA adducts of cisdiamminedichloroplatinum(II) and its trans isomer inhibit RNA polymerase II differentially in vivo. Biochemistry 34: 14783-14791.

15. Kuhad A, Tirkey N, Pilkhwal S, Chopra K (2006) 6-Gingerol prevents cisplatininduced acute renal failure in rats. Biofactors 26: 189-200.

16. Lee S, Moon SO, Kim W, Sung MJ, Kim DH, et al. (2006) Protective role of L-2oxothiazolidine-4-carboxylic acid in cisplatin-induced renal injury. Nephrol Dia Transplant 21: 2085-2095.

17. Sugihara K, Gemba M (1986) Modification of cisplatin toxicity by antioxidants Jpn J Pharmacol 40: 353-355.

18. Hannemann J, Baumann K (1988) Cisplatin-induced lipid peroxidation and decrease of gluconeogenesis in rat kidney cortex: different effects of antioxidants and radical scavengers. Toxicology 51: 119-132.

19. Sadzuka Y, Shoji T, Takino Y (1992) Effect of cisplatin on the activities of enzymes which protect against lipid peroxidation. Biochem Pharmacol 43 . $1872-1875$.

20. Zhang JG, Lindup WE (1993) Role of mitochondria in cisplatin-induced oxidative damage exhibited by rat renal cortical slices. Biochem Pharmacol 45: 2215-2222.

21. Weijl NI, Hopman GD, Wipkink-Bakker A, Lentjes EG, Berger HM, et al. (1998) Cisplastin combination chemotherapy induces a fall in plasma antioxidants of cancer patients. Ann Oncol 9: 1331-7.

22. Leclere L, Cutsem PV, Michiels C (2013) Anti-cancer activities of pH- or heatmodified pectin. Front Pharmacol 4: 128

23. Chasin M, Langer R (1990) Biodegradable Polymers as Drug delivery Systems. Marcel Dekker, Inc, New York 71-220

24. Rolin C, Nielsen BU, Glahn PE (1998) Pectin. In: Dumitrui S (ed.) Polysaccharides. Structural diversity and functional versatility, Marcel Dekker, Inc., New York, pp: 377-431.

25. Elisabetta E, Rita C, Giovanni L (2001) Pectin-based microspheres: a preformulation study. NewYork Acad Sci 99: 160-179.

26. Wakerly Z, Fell JT, Attwood D, Parkins D (1997) Studies on drug release from pectin/ethylcellulose film-coated tablets -a potential colonic delivery system. International Journal of Pharmaceutics 153: 219-22.

27. Wong TW, Chan LW, Lee HY, Heng PW (2002) Release characteristics of pectin microspheres prepared by an emulsification technique. J Microencapsul 19: $511-522$

28. Tomida H, Yasufuku T, Fujii T, Kondo Y, Kai T, et al. (2010) Polysaccharides as potential antioxidative compounds for extended-release matrix tablets. Carbohydr Res 345: 82-86.

29. Li SP, Zhang GH, Zeng Q, Huang ZG, Wang YT, et al. (2006) Hypoglycemic activity of polysaccharide, with antioxidation, isolated from cultured Cordyceps mycelia. Phytomedicine 13: 428-433.

30. Mateos-Apariciol, Mateos-Peinado C, Jiménez-Escrig A, Rupérez P (2010) Multifunctional antioxidant activity of polysaccharide fractions from the soybean byproductokara. Carbohydr.Polym 82: 245-250.

31. Yang SS, Cheng KT, Lin YS, Liu YW, Hou WC (2004) Pectin hydroxamic acids exhibit antioxidant activities in vitro. J Agric Food Chem 52: 4270-4273.

32. Verma AK, Sachin K (2008) Novel Hydrophilic Drug Polymer Nanoconjugates of Cisplatin Showing Long Blood Retention Profile - Its Release Kinetics, Cellular Uptake and Bio-Distribution. Current Drug Delivery 5: 121-129.

33. Sau A, Pellizzari Tregno F, Valentino F, Federici G, Caccuri AM (2010) Glutathione transferases and development of new principles to overcome drug resistance. Arch Biochem Biophys 500: 116-122.
34. Chasseaud LF (1979) The role of glutathione and glutathione S-transferases in the metabolism of chemical carcinogens and other electrophilic agents. Adv Cancer Res 29: 175-274.

35. Mannervik B (1985) The isoenzymes of glutathione transferase. Adv Enzymol Relat Areas Mol Biol 57: 357-417.

36. Lu H, Gunuwardena S, Cui JY, Yoo B, Zhong XB, et al. (2013) RNA-sequencing quantification of hepatic ontogeny and tissue distribution of mRNAs of phase-II enzymes in mice. Drug MetabDispos 41: 844-857.

37. Verma AK, SachinK, Saxena A, Bohidar HB (2005) Release kinetics from bio polymeric nanoparticles encapsulating protein synthesis inhibitorcycloheximide, for possible therapeutic applications. Curr. Pharm. Biotechno 6(2): $121-130$

38. Sanwlani S, Rawat K, PalM, Bohidar HB, Verma AK (2014) Cellular uptake induced biotoxicity of surface-modified CdSe quantum dots. J Nanopart Res 16: 2382.

39. Julien DC, Richardson CC, Beaux MF 2nd, Mcllroy DN, Hill RA (2010) In vitro proliferating cell models to study cytotoxicity of silica nanowires. Nanomedicine 6: 84-92.

40. Rabah SO (2010) Acute Taxol nephrotoxicity: Histological and ultrastructura studies of mice kidney parenchyma. Saudi J Biol Sci 17: 105-114.

41. Verma AK, Chanchal A, Pandey RP, Vohra R, IslamN, et al. (2012) .Pharmacokinetics and Biodistribution of Paclitaxel-Gelatin Nanoparticles. International Journal of Green Nanotechnology 4(4): 500-510

42. Oakley A (2011) Glutathione transferases: a structural perspective. Drug Metab Rev 43: 138-151.

43. Lo HW, Ali-Osman F (2007) Genetic polymorphism and function of glutathione S-transferases in tumor drug resistance. Curr Opin Pharmacol 7: 367-374.

44. Wu G, Fang YZ, Yang S, Lupton JR, Turner ND (2004) Glutathione metabolism and its implications for health. J Nutr 134: 489-492.

45. Nagar R, Khan AR, Poonia A, Mishra PK, Singh S (2015) Metabolism of cisplatin in the organs of Rattus norvegicus: role of Glutathione S-transferase P1. Eur J Drug Metab Pharmacokinet 40: 45-51.

46. Ajith TA, Usha S, Nivitha V (2007) Ascorbic acid and alpha-tocopherol protect anticancer drug cisplatin induced nephrotoxicity in mice: a comparative study. Clin Chim Acta 375: 82-86.

47. Pratibha R, Sameer R, Rataboli PV, Bhiwgade DA, Dhume CY (2006) Enzymatic studies of cisplatin induced oxidative stress in hepatic tissue of rats Eur J Pharmacol 532: 290-293.

48. Wilhelm EA, Bortolatto CF, Nogueira CW (2012) p-Methoxyl-diphenyl diselenide protects against cisplatin-induced renal toxicity in mice. Food Chem Toxicol 50 : 1187-1193.

49. Casalino E, Sblano C, Landriscina V, Calzaretti G, Landriscina C (2004) Rat liver glutathione S-transferase activity stimulation following acute cadmium or manganese intoxication. Toxicology 200: 29-38.

50. Mylonas C, Kouretas D (1999) Lipid peroxidation and tissue damage. In Vivo 13: $295-309$

51. Matsushima H, Yonemura K, Ohishi K, Hishida A (1998) The role of oxygen free radicals in cisplatin-induced acute renal failure in rats. J Lab Clin Med 131: 518-526.

52. Dedon PC, Borch RF (1987) Characterization of the reactions of platinum antitumor agents with biologic and nonbiologic sulfur-containing nucleophiles. Biochem Pharmacol 36: 1955-1964.

53. Jamieson ER, Lippard SJ (1999) Structure, Recognition, and Processing of Cisplatin-DNAAdducts. Chem Rev 99: 2467-2498.

54. Lange RC, Spencer RP, Harder HC (1973) The antitumor agent cis- $\mathrm{Pt}(\mathrm{NH} 3$ $2 \mathrm{Cl} 2$ : distribution studies and dose calculations for $193 \mathrm{~m} \mathrm{Pt}$ and $195 \mathrm{~m} \mathrm{Pt}$. J Nucl Med 14: 191-195

55. Bénard P, Desplanches G, Macquet JP, Simon J (1983) Whole-body autoradiographic study of the distribution of $195 \mathrm{mPt}$ in healthy and tumorbearing mice treated with labeled cisplatin. Cancer Treat Rep 67: 457-466.

56. Sadzuka Y, Shimizu Y, Takino Y, Hirota S (1994) Protection against cisplatininduced nephrotoxicity in the rat by inducers and an inhibitor of glutathione S-transferase. Biochem Pharmacol 48: 453-459. 
Citation: Verma AK, Leekha A (2016) Elucidation of Glutathione-S-transferase Activity Induced by Pectin-Cisplatin Nano-conjugates for Optimization of New Therapeutic Strategies. J Nanomed Nanotechnol 7: 391. doi:10.4172/2157-7439.1000391

57. Hanigan MH, Devarajan P (2003) Cisplatin nephrotoxicity: molecular mechanisms. Cancer Ther 1: 47-61.

58. Santos NA, Catao CS, Martins NM, Curti C, Bianchi ML, et al. (2007) Cisplatininduced nephrotoxicity is associated with oxidative stress, redox state unbalance, impairment of energetic metabolism and apoptosis in rat kidney mitochondria. Arch. Toxicol 81: 495-504.

59. Duncan R; N-(2-Hydroxypropyl)methacrylamide copolymer conjugates. In Polymeric Drug Delivery Systems. By Kwon, G.S. Ed.; Marcel Dekker: New York. 2005a: 1-92.

60. Duncan R (2005b) Targeting and intracellular delivery of drugs. In: Meyers RA (ed.) Encyclopedia of Molecular Cell Biology and Molecular Medicine. Weinheim. Germany: Wiley-VCHVerlag pp: 163-204.

61. Leclere L, Cutsem PV, Michiels C (2013) Anti-cancer activities of pH- or heatmodified pectin. Front Pharmacol 4: 128

62. Blair BG, Larson CA, Safaei R, Howell SB (2009) Copper transporter 2 regulates the cellular accumulation and cytotoxicity of Cisplatin and Carboplatin. Clin Cancer Res 15: 4312-4321.

63. Sedletska Y, Giraud-Panis MJ, Malinge JM (2005) Cis is a DNA-damaging antitumour compound triggering multifactorial biochemical responses in cancer cells: importance of apoptotic pathways. Current Medicinal Chemistry: AntiCancer Agents 5: 251-265.
64. Macleod GS, Fell JT, Collett JH (1999) An in vitro investigation into the potentia for bimodal drug release from pectin/chitosan/HPMC-coated tablets. Int J Pharm 188: 11-18.

65. Ofori-Kwakye K, Fell JT (2003) Biphasic drug release from film-coated tablets. Int J Pharm 250: 431-440.

66. He W, Du Q, Cao DY, Xiang B, Fan LF (2008) Study on colon-specific pectin/ethylcellulose film-coated 5-fluorouracil pellets in rats. Int J Pharm 348: $35-45$.

67. Semdé R, Amighi K, Pierre D, Devleeschouwer MJ, Moës AJ (1998) Leaching of pectin from mixed pectin/insoluble polymer films intended for colonic drug delivery. Int J Pharm 174: 233-241.

68. Martens-de Kemp SR, Dalm SU, Wijnolts FM, Brink A, Honeywell RJ, et al (2013) DNA-bound platinum is the major determinant of cisplatin sensitivity in head and neck squamous carcinoma cells. PLoS One 8: e61555.

69. Bischin C, Lupan A, Taciuc V, Silaghi-Dumitrescu R (2011) Interactions between proteins and platinum-containing anti-cancer drugs. Mini Rev Med Chem 11 214-224.

70. Cepeda V, Fuertes MA, Castilla J, Alonso C, Quevedo C, et al. (2007) Biochemical mechanisms of cisplatin cytotoxicity. Anticancer Agents Med Chem 7: 3-18. 